\title{
Bone marrow stromal cell survival, migration, and differentiation following acute and delayed transplantation into the moderately contused adult rat thoracic spinal cord
}

\author{
R D S Nandoe Tewarie ${ }^{1,2,3, \text { * }}$, A Hurtado ${ }^{1,2, *}, \mathrm{~J}$ A Grotenhuis ${ }^{3}$, M Oudega $^{1}$ \\ ${ }^{1}$ The International Center for Spinal Cord Injury, Kennedy Krieger Institute and the Department of Neurology, Johns Hopkins \\ University School of Medicine, Baltimore, Maryland, USA; ${ }^{2}$ The Miami Project to Cure Paralysis, University of Miami Miller \\ School of Medicine, Miami, Florida, USA; ${ }^{3}$ Department of Neurosurgery, Radboud University Nijmegen Medical Center, Nijmegen, \\ The Netherlands
}

Bone marrow stromal cells (BMSC) are considered for cell-based strategies for spinal cord repair. We transplanted autologous rat BMSC (female Sprague-Dawley, 160-180gr), lentivirally transduced to express green fluorescent protein (GFP), acutely (15 min post-injury) and delayed (3, 7, and 21 days post-injury) into the moderately contused adult rat thoracic spinal cord and investigated their survival, migration, and differentiation at $15 \mathrm{~min}, 3,7$, and 28 days post-injection. The percentages of GFP-positive BMSC in the contusion at 3, 7, and 28 days post-injection, relative to the numbers at 15 min post-injection, were $59 \%, 32 \%$, and $0.02 \%$ after acute and an average of $51 \%$, $22 \%$, and $0.8 \%$ after delayed transplantation, respectively. BMSC death at 7 days postinjection was significantly lower after acute injections (68\%) than after 7- and 21-day delayed injections (91\%). At 28 days post-injection, the number of surviving BMSC in the contusion was similar in all paradigms. About $1.2 \%$ of the BMSC grafted in the 3-day old contusion had migrated into the rostral (80\% of migrated cells) and caudal $(20 \%)$ white matter 7 days later. Nestin expression in the contused spinal cord was temporarily and unaffected by BMSC transplantation. Nestin-positive BMSC were found within the transplant but only at $15 \mathrm{~min}$ post-injection. We provide evidence that BMSC grafted acutely or delayed into a moderate contusion in the rat spinal cord survive poorly, migrate into adjacent spinal tissue only under specific conditions, and do not differentiate into neural stem/ progenitor cells or astrocytes, which together may restrict their effectiveness for spinal cord repair.

Keywords: spinal cord, bone marrow, stem cells, GFP, survival, migration

Cell Research (2008) 18:s100. doi: 10.1038/cr.2008.190; published online 4 August 2008

\footnotetext{
*These two authors contributed equally to this work

Correspondence: Rishi Nandoe Tewarie

E-mail: R.D.S.Nandoe@nch.umcn.nl
}

Rishi Nandoe Tewarie has completed medical school in 2003 and am currently a resident Neurosurgery in the Netherlands. Over the last few years he has been working on my $\mathrm{PhD}$ studies transplanting mesenchymal stem cells in the injured adult rat thoracic spinal cord at The Miami Project to Cure Paralysis (Miami University) and Kennedy Krieger Institute (Johns Hopkins University, Baltimore). At present he is back in clinics and have planned to focus his future career more towards clinical research in spinal cord injury and stem cells. 